\title{
Diversified Production of Recycled Aggregate Concrete Mixture with the Addition of Single and Hybrid Fibers
}

\author{
Sallehan Ismail ${ }^{1 *}$, Wan Nur Syazwani Wan Mohammad ${ }^{1}$, Mahyuddin Ramli ${ }^{2}$ \\ ${ }^{\text {I}}$ Faculty of Architecture, Planning \& Surveying, Universiti Teknologi MARA, Perak Branch, Seri Iskandar Campus, \\ 32610 Seri Iskandar, Perak, Malaysia \\ ${ }^{2}$ School of Housing, Building and Planning, Universiti Sains Malaysia, 11800 Pulau Pinang, Malaysia \\ *Corresponding author E-mail: salle865@perak.uitm.edu.my
}

\begin{abstract}
The low strength property of recycled concrete aggregates (RCAs) limits its widespread application in the production of high-strength recycled aggregate concrete (RAC). In this study, RCA properties were improved prior to its incorporation into an RAC mixture through surface treatment. This mixture was subsequently diversified considering the benefits of adding various fiber-reinforced systems to enhance RAC performance. Two types of short discrete synthetic fibers, namely, polyolefin and polypropylene, were added in single and hybrid forms. This study aimed to investigate the effectiveness of the diversified modification of RAC mixture production on the mechanical strength of the resulting RAC. Various properties of the modified RAC were analyzed. Although the modified RAC mixture using treated RCA significantly enhanced the mechanical strength of this RAC, the diversification of the RAC mixture with additional polyolefin and polypropylene fibers, particularly in the hybrid form, further optimized the RAC performance.
\end{abstract}

Keywords: Hybrid fiber; polyolefin fiber; polypropylene fiber; recycled aggregate concrete; treated recycled concrete aggregate.

\section{Introduction}

The utilization of recycled concrete aggregates (RCAs) in largescale productions of recycled aggregate concrete (RAC) facilitates a sustainable construction by maximizing the use of existing resources and reducing environmental pollution $[1,2]$. However, the construction industry still doubts the use of RAC in structural constructions. This condition is caused by the low qualities of RCA, such as its high water absorption and low mechanical strength and density compared with those of natural aggregates [3$5]$. Consequently, many researchers $[6,7]$ have reported that adding RCA in new concrete mixtures, either as a partial or full replacement, tend to jeopardize the mechanical strength and durability of concrete.

Hence, in our previous research [8], we developed new treatment methods to reduce the detrimental effects of RCA before its addition in concrete mixtures. These techniques significantly reduced the porosity and improved the surface contact between the RCA and the new cement paste in the new concrete. However, this method is limited by its tendency to strengthen the surface contact between the RCA and new cement mortar rather than the bond between the RCA and the old cement mortar. This phenomenon causes the latter components to become the weakest point in the composite system, which may likely cause the concrete to fail at this region when subjected to load conditions. According to its nature, high-strength concrete fails differently during loading than normal concrete; cracks can possibly pass through the aggregate rather than at the interface between the aggregate and cement matrix [7]. In addition to procedures for improving RCA quality through surface treatment method, the use of fiber reinforcement systems to enhance RAC properties should be considered. The addition of fibers makes the concrete homogeneous and isotropic, as well as transforms it from a brittle to a ductile material [9]. Short-cut fiber mainly functions as a secondary reinforcement in concrete to control crack propagation.

The enhancing effect of fiber, especially in its hybrid form, for some RAC properties remains poorly reported. In this study, the mixture proportion of RAC, which consisted of the treated coarse RCA developed from our previous research [8], was further diversified with the inclusion of various fiber-reinforced systems. Two types of synthetic fibers, namely, polyolefin and polypropylene, were added in the RAC mixture. This study mainly aimed to evaluate the influence of various fiber-reinforced systems (single and hybrid forms) on the mechanical properties of the resulting RAC. In addition, this study determined the most appropriate fiber proportion that can significantly enhance the mechanical performance of RAC. Scanning electron microscopy (SEM) analysis was conducted to visualize the micro-structural behavior of the resulting related concrete mixtures. The findings of this study are necessary to understand the potential of this new approach toward efficient RAC production.

\section{Method}

A commercial ordinary portland cement type 1 according to American Society of Testing Materials with a specific gravity of $3.15 \mathrm{~g} / \mathrm{cm}^{3}$ was used for the experiment. In this study, the natural coarse aggregate used was crushed granite, and the coarse RCA was generated by crushing concrete debris and sieved to obtain a maximum particle size of $20 \mathrm{~mm}$. In the present study, two types of coarse RCAs were produced, namely, treated and untreated. Treated RCA was prepared by modifying the RCA surface structure in two stages of surface treatment methods: (1) pre-soaking in hydrochloric acid at 0.5 molar concentration and then (2) coating 
the RCA with wollastonite (calcium metasilicate) powder. The treatment process was described in detail in our previous study [8]. Table 1 shows the properties of all types of aggregates in terms of physical and mechanical strength characteristics. Two types of synthetic fibers were used: (1) polyolefin (PO) fiber type, Barchip 54 , and (2) fibrillated polypropylene (PP) fibers. Table 2 presents the different properties of the polyolefin and polypropylene fibers Certain amounts of the superplasticizer were added to maintain concrete workability.

All concrete mixture proportions were produced in accordance with the British method [10]. The water/cement ratios for all mixtures were kept constant at 0.41 to achieve a compressive strength of $50 \mathrm{MPa}$ for 28 days. The amount of coarse aggregates for all RAC mixtures were kept constant by replacing the natural coarse aggregate with untreated or treated RCA at $60 \%$ (by weight). Meanwhile, the dosage schemes of either individual or hybrid fibers added to the respective RAC mixture were kept constant at a total volume fraction rate of $1.2 \%$ (by volume of the cement). Overall, nine series of mixtures were prepared depending on the type of coarse aggregate. Table 3 shows the varying volume fractions of fiber contents.

All concrete mixtures were mixed according to the sequence prescribed in BS1881-125. After casting, all concrete specimens were removed from the mold, cured in open air for $24 \mathrm{~h}$, and then fully immersed in water at normal temperature until testing age was reached. In this study, the mechanical strengths, namely, compressive and flexural strength tests, of RAC were investigated, and both test results were determined at ages of 7, 28, 90, 180, and 300 days. The compressive strength test was carried out in accordance with BS EN 12390-3 on 100 mm concrete cubes, whereas flexural strength test was conducted according to BS EN 12390-5 on $100 \times$ $100 \times 500 \mathrm{~mm}$ concrete prism. SEM analysis was used to examine the microstructure of the interfacial transition zone between the aggregates and the new cement matrix. Meanwhile, ultrasonic pulse velocity (UPV), a non-destructive test that measures the speed of ultrasonic pulse that passes through the test materials, was conducted in accordance with BS 1881-203 and performed on a concrete prism similar to the specimens used in the flexural strength test.

Table 1: Coarse aggregate properties [8]

\begin{tabular}{|l|l|c|c|c|}
\hline $\begin{array}{l}\text { Properties of } \\
\text { aggregate }\end{array}$ & $\begin{array}{c}\text { Sizes of } \\
\text { aggregate }\end{array}$ & $\begin{array}{c}\text { Natural } \\
\text { aggregate }\end{array}$ & $\begin{array}{c}\text { Untreated } \\
\text { RCA }\end{array}$ & $\begin{array}{c}\text { Treat } \\
\text { ed } \\
\text { RCA }\end{array}$ \\
\hline $\begin{array}{l}\text { Particle density } \\
\left(\mathrm{Mg} / \mathrm{m}^{3}\right)\end{array}$ & $20 \mathrm{~mm}$ & 2.65 & 2.59 & 2.61 \\
\cline { 2 - 5 } & $10 \mathrm{~mm}$ & 2.63 & 2.54 & 2.61 \\
\hline $\begin{array}{l}\text { Water absorption } \\
(\%)\end{array}$ & $20 \mathrm{~mm}$ & 0.60 & 4.44 & 3.48 \\
\cline { 2 - 5 } & $10 \mathrm{~mm}$ & 0.70 & 5.58 & 4.48 \\
\hline $\begin{array}{l}\text { Aggregate crush- } \\
\text { ing value (\%) }\end{array}$ & $14 \mathrm{~mm}$ & 24.32 & 29.15 & $\begin{array}{c}28.3 \\
4\end{array}$ \\
\hline $\begin{array}{l}\text { Aggregate impact } \\
\text { value (\%) }\end{array}$ & $14 \mathrm{~mm}$ & 13.98 & 21.78 & $\begin{array}{c}19.2 \\
6\end{array}$ \\
\hline $\begin{array}{l}\text { LA abrasion } \\
\text { value (\%) }\end{array}$ & $14 \mathrm{~mm}$ & 34.76 & 39.12 & $\begin{array}{c}36.7 \\
6\end{array}$ \\
\hline
\end{tabular}

Table 2: Specifications of polyolefin and fibrillated polypropylene fibers

\begin{tabular}{|l|c|c|}
\hline \multicolumn{1}{|c|}{ Item } & \multicolumn{2}{c|}{ Specifications } \\
\hline & Polyolefin & Polypropylene \\
\hline Product types & Barchip 54 & Fibrillated \\
\hline Average Length & $27^{ \pm} 2 \mathrm{~mm}$ & $15 \mathrm{~mm}$ \\
\hline Tensile Strength & $640 \mathrm{MPa}$ & $0.31-0.42 \mathrm{kN} / \mathrm{mm}^{2}$ \\
\hline Specific Gravity & $0.92 \mathrm{~g} / \mathrm{cm}^{3}$ & $0.9 \mathrm{~g} / \mathrm{cm}^{3}$ \\
\hline Modulus of elasticity & $10 \mathrm{GPa}$ & $3.5 \mathrm{kN} / \mathrm{mm}^{2}$ \\
\hline Melting Point & $159^{\circ} \mathrm{C}-179^{\circ} \mathrm{C}$ & $160^{\circ} \mathrm{C}-170^{\circ} \mathrm{C}$ \\
\hline Ignition Point & $>450^{\circ} \mathrm{C}$ & $590^{\circ} \mathrm{C}$ \\
\hline
\end{tabular}

Table 3: Details of mixing proportion

\begin{tabular}{|c|c|c|c|c|c|c|c|c|}
\hline \multirow[t]{3}{*}{$\begin{array}{l}\text { Speci- } \\
\text { men }\end{array}$} & \multirow[t]{3}{*}{$\begin{array}{c}\mathrm{Ce}- \\
\text { ment } \\
\mathrm{kg} / \mathrm{m}^{3}\end{array}$} & \multirow[t]{3}{*}{$\begin{array}{c}\text { Wa- } \\
\text { ter } \\
\mathrm{kg} / \mathrm{m}\end{array}$} & \multirow{2}{*}{\multicolumn{2}{|c|}{$\begin{array}{c}\text { Coarse ag- } \\
\text { gregate } \mathrm{kg} / \mathrm{m}^{3}\end{array}$}} & \multirow[t]{3}{*}{$\begin{array}{l}\text { Sand } \\
\mathrm{kg} / \mathrm{m}\end{array}$} & \multirow[t]{3}{*}{$\begin{array}{l}\text { SP } \\
(\% \\
)\end{array}$} & \multicolumn{2}{|c|}{$\begin{array}{c}\text { Vol. frac- } \\
\text { tion of } \\
\text { fiber }(\%)\end{array}$} \\
\hline & & & & & & & $\mathrm{PO}$ & PP \\
\hline & & & $\begin{array}{c}\text { Grav } \\
\text { el }\end{array}$ & $\begin{array}{c}\mathrm{RC} \\
\mathrm{A}\end{array}$ & & & $\begin{array}{l}\text { fi- } \\
\text { ber }\end{array}$ & $\begin{array}{l}\text { fi- } \\
\text { ber }\end{array}$ \\
\hline $\mathrm{CO}$ & 512 & 210 & 956 & - & 722 & 0 & - & - \\
\hline RO & 512 & 210 & 382 & 574 & 722 & 0 & - & - \\
\hline TR & 512 & 210 & 382 & 574 & 722 & 0.2 & - & - \\
\hline $\mathrm{BF}$ & 512 & 210 & 382 & 574 & 722 & 0.3 & 1.2 & - \\
\hline $\mathrm{PF}$ & 512 & 210 & 382 & 574 & 722 & 0.3 & - & 1.2 \\
\hline HB1 & 512 & 210 & 382 & 574 & 722 & 0.3 & $\begin{array}{c}0.9 \\
6\end{array}$ & $\begin{array}{c}0.2 \\
4\end{array}$ \\
\hline HB2 & 512 & 210 & 382 & 574 & 722 & 0.3 & $\begin{array}{c}0.7 \\
2\end{array}$ & $\begin{array}{c}0.4 \\
8\end{array}$ \\
\hline HB3 & 512 & 210 & 382 & 574 & 722 & 0.3 & $\begin{array}{c}0.4 \\
8\end{array}$ & $\begin{array}{c}0.7 \\
2\end{array}$ \\
\hline HB4 & 512 & 210 & 382 & 574 & 722 & 0.3 & $\begin{array}{c}0.2 \\
4\end{array}$ & $\begin{array}{c}0.9 \\
6 \\
\end{array}$ \\
\hline
\end{tabular}

\section{Results and Discussion}

The changes in the compressive strength of all tested specimens at ages 7-300 days are presented in Fig. 1. In this study, the compressive strengths of the RAC specimens prepared with different types of coarse aggregates and fiber-reinforced systems were compared with that of normal concrete (CO). In Fig. 1, the addition of $60 \%$ untreated RCA to replace the natural coarse aggregate significantly affected the compressive strength of the RAC. However, the results suggested that the development of the compressive strength of the RAC with treated RCA can be enhanced by adding certain amounts of fibers. The findings indicate that the RAC specimens that were incorporated with either single polyolefin or polypropylene fiber exhibit improved compressive strength than the non-fibrous RAC and greater strength than the CO specimen. The RAC mixture reinforced with polyolefin fiber showed increased strength from $3 \%$ to $9 \%$, whereas the rate increased from $1 \%$ to $10 \%$, which was higher than that of the CO specimens when polypropylene was included in the mixture, as indicated in the comparison across all testing days.

Compared with single-fiber specimens, some hybrid fibrous specimens greatly maximized the compressive strength performance at relative testing ages. This study showed that consistent compressive strength results can be observed for the HB4 specimen. The maximum compressive strength of this specimen was greater than that of other specimens, particularly at the long-term ages of 90, 180, and 300 days. This improvement may be attributed to the synergetic effect of these fibers when used in its hybrid form. The effect of different aspect ratios, volume fractions, and tensile strength values among these fibers might have induced the arrest propagation of cracks at different levels as well as the micro and macro cracks in the concrete structure $[11,12]$. As observed in this study, the primary effect of fiber in strengthening the matrix is not through the increased capacity to carry the applied load, but to strengthen the brittleness in the matrix structure by inducing crack bridging capability, which provides a crack control mechanism that delays failure [11]. This finding was confirmed by the SEM image shown in Fig. 2, which indicated that the fibers can chase crack propagation. 


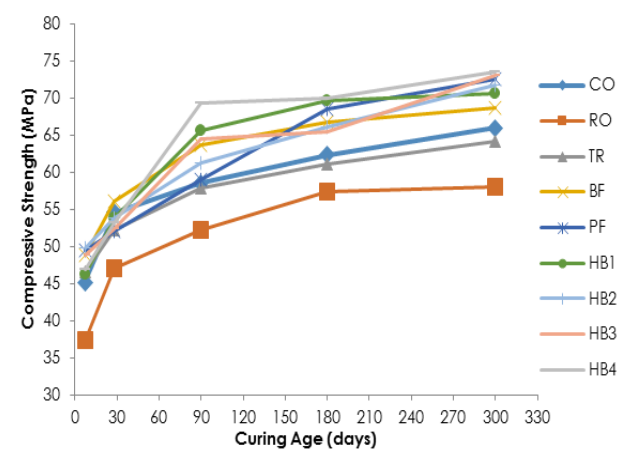

Fig. 1: Compressive strength versus curing age for all tested specimens
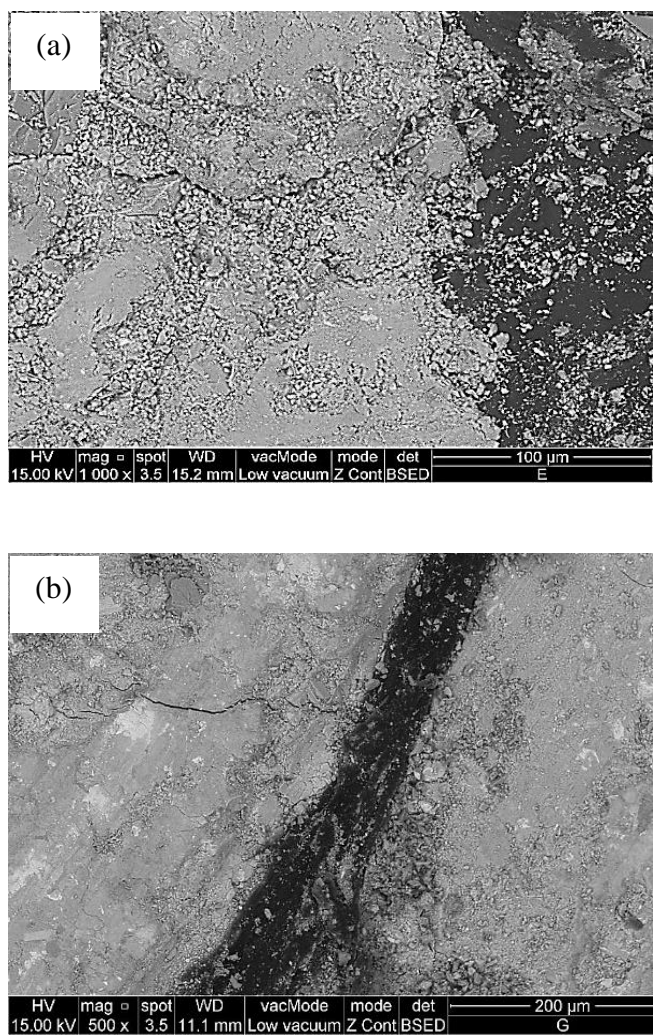

Fig. 2: Roles of (a) polyolefin and (b) polypropylene fibers in resisting crack propagation

Fig. 3 shows the relationship between flexural strength behavior and testing age of specimens. The results from this study indicated that the flexural strength of concrete with coarse RCA generally tended to be lower than those of control (CO) concrete. However, the addition of fibers remarkably enhanced the flexural strength of RAC. Despite the strength that single and hybrid specimens gain with prolonged water curing, this gain was lower than that of $\mathrm{CO}$, especially at earlier ages of 28 and 90 days; however, the gain in flexural strength increased at later curing periods. In this case, the availability of fibers might require cement hydration time to strengthen the interface bond between the fiber and matrix. This phenomenon can be explained by the SEM results. The interface layers are loose, and some pores appear because of the lack of contact between the fibers and matrix during initial curing [see Fig. 4(a) and Fig. 5(a)]. The high concentration of portland leads to the porosity in the fiber-matrix interface during early hydration [13]. Meanwhile, SEM examination results of fibrous specimens at 300 days showed that the side surface of both fibers was covered with densely hydrated cement matrix, as shown in Fig. 4(b) and Fig. 5(b). The figures also show a certain hydrated cement matrix, indicating a strong bond between the fibers and cement matrix during long-term curing on the surface of both fibers [14]. The gain in flexural strength for the given testing ages of specimens with hybrid fiber is generally not as evident compared with single- fiber specimens, and in certain cases, the results for these specimens are better. The profile gain analysis in the flexural strength of RAC specimens with hybrid fiber at 28 days indicated that the flexural strength values of HB2, HB3, and HB4 were only $99 \%$, $95 \%$, and $95 \%$, respectively, compared with that of CO. The flexural strength showed that further increments higher than that of $\mathrm{CO}$ after the curing period were prolonged to 180 and 300 days. At the curing age of 300 days, the highest flexural strength was found in the group of RAC specimens with hybrid fibers. Their overall strength reached approximately $7 \mathrm{MPa}$. This result might suggest that the dispersion of different types of fiber strengthens the bond between the fibers and that RAC specimens that benefitted from the cement matrix occurrence through the reinforced effects of hybridization (i.e., ability to resist and bridge cracks) $[11,15]$. Hence, a weak link in the RAC caused by the weak and low quality of RCA can be compensated by strengthening the capability by fiber contents in the matrix.

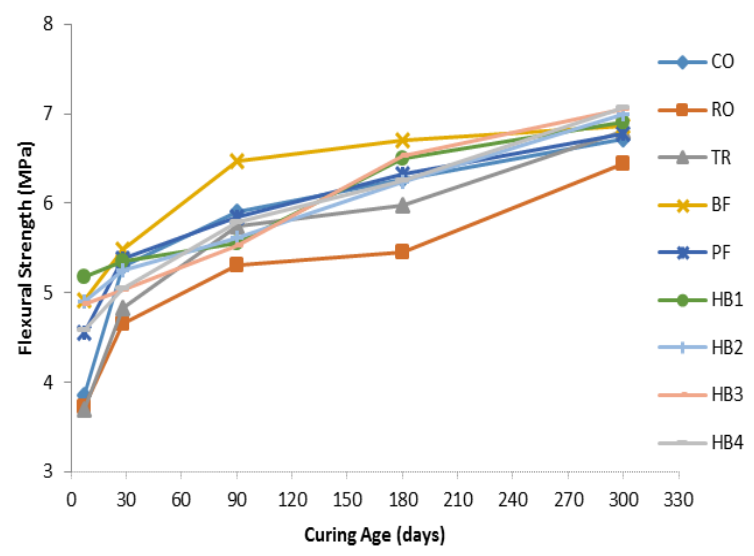

Fig. 3: Flexural strength versus curing age of tested specimens
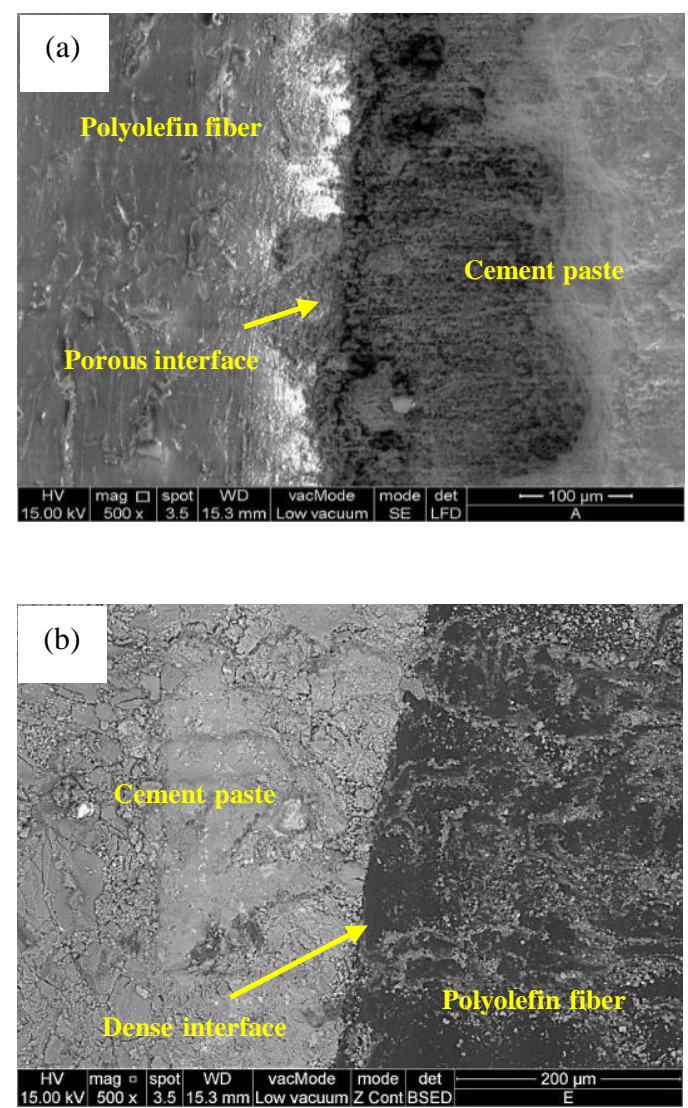

Fig. 4: Interface between the polyolefin fiber and cement paste at (a) 28 days and (b) 300 days 

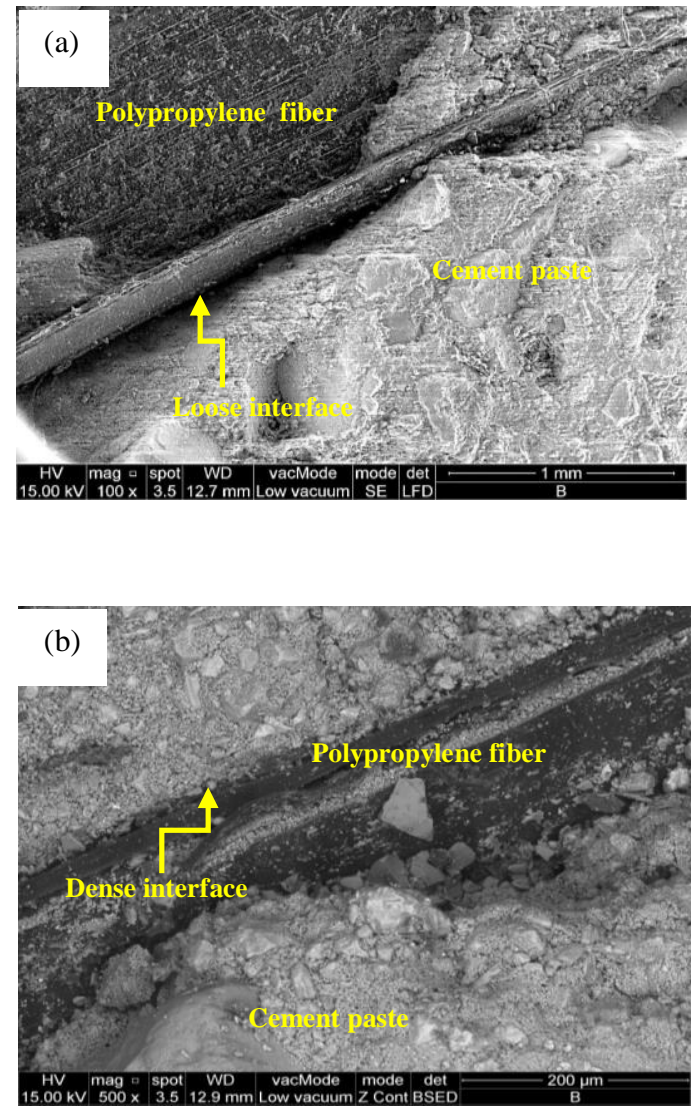

Fig. 5: Interface between the polypropylene fiber and cement paste at (a) 28 days and (b) 300 days

The UPV value gains of all specimens from ages 7 days to 300 days are displayed in Fig. 6. Overall, results showed that the UPV values of all specimens increased with prolonged curing age. Findings indicated that the UPV values of all specimens at up to 300 days varied, but all the specimen values fell within the range above $4.40 \mathrm{~km} / \mathrm{s}$. This finding suggests that all resulting specimens produce good quality of concrete and are considered without the honeycomb structure created inside the specimens [16]. For a given concrete mixture and testing age, the maximum UPV value is pronounced in $\mathrm{CO}$ specimens, whereas the lowest value is probably demonstrated in the RAC mixture with untreated RCA, as demonstrated by RO specimens. This phenomenon is attributed to the lower density of the RCA than the natural coarse aggregate, resulting in more pores in RAC than normal concrete. These results are consistent with those of other studies [6]. By contrast, the UPV values gained by TR were slightly higher than those of RO. This finding can also be attributed to the decreased pore structure within RAC because of surface treatment effects. Nevertheless, RAC specimens incorporated with fiber appear to benefit from the prolonged curing period with respect to UPV. This finding suggests that prolonged curing period enhances the bond between the fiber and cement matrix; thus, the structure bond within specimens is improved.

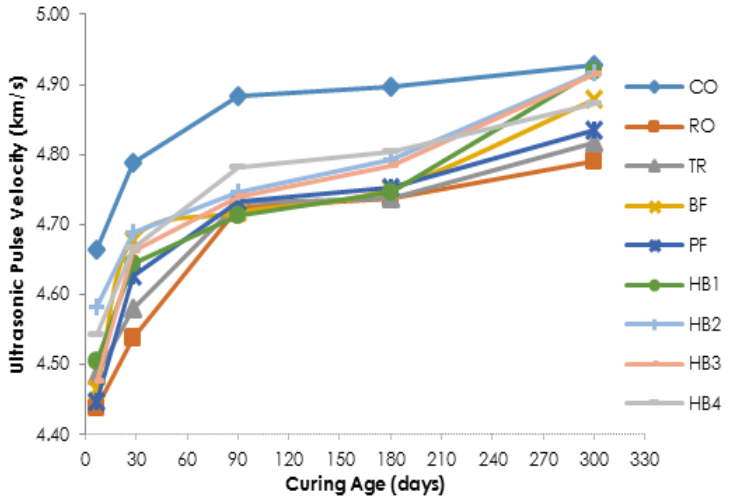

Fig. 6: Ultrasonic pulse velocity versus curing age of tested specimens

\section{Conclusion}

The modification of the RAC mixture by including treated RCA significantly enhances its mechanical strength properties. However, further extending the diversity of the production of RAC mixture by incorporating different volume ratios of polyolefin and polypropylene fibers, particularly in hybrid forms, can optimize the results. The optimum compressive strength was obtained by modifying the RAC in HB4, which produced the highest compressive strength performance among other specimens, particularly at long-term curing ages. Moreover, other mechanical strength properties of modified RAC in terms of flexural strength were also superior to those of normal concrete and unmodified RAC. This finding was confirmed by SEM analysis, indicating that the uniform position and orientation of polyolefin and polypropylene fibers enhanced the arrest mechanism and hindered the different angles and scales of microcrack growths in the cement matrix of the RAC. Meanwhile, RAC specimens with fiber appeared to benefit from prolonged curing period with respect to UPV.

\section{Acknowledgement}

The authors are grateful to Universiti Teknologi MARA and Universiti Sains Malaysia for its research facilities support as well as to all parties that have contributed in this project.

\section{References}

[1] S. Ismail, et al., "Sustainable Aggregates: The Potential and Challenge for Natural Resources Conservation," Procedia - Social and Behavioral Sciences, vol. 101, pp. 100-109, 2013.

[2] S. Marinkovic, et al., "Comparative environmental assessment of natural and recycled aggregate concrete," Waste Management, vol. 30, pp. 2255-2264, 2010.

[3] A. K. Padmini, et al., "Influence of parent concrete on the properties of recycled aggregate concrete," Construction and Building Materials, vol. 23, pp. 829-836, 2009.

[4] V. W. Y. Tam, et al., "Microstructural analysis of recycled aggregate concrete produced from two-stage mixing approach," Cement and Concrete Research, vol. 35, pp. 1195-1203, 2005.

[5] S. Ismail and M. Ramli, "Effect of Different Moisture States of Surface-Treated Recycled Concrete Aggregate on Properties of Fresh and Hardened Concrete," International Journal of Civil, Architectural, Structural and Construction Engineering vol. 8, pp. 65-71, 2014.

[6] W. H. Kwan, et al., "Influence of the amount of recycled coarse aggregate in concrete design and durability properties," Construction and Building Materials, vol. 26, pp. 565-573, 2012.

[7] M. Etxeberria, et al., "Influence of amount of recycled coarse aggregates and production process on properties of recycled aggregate concrete," Cement and Concrete Research, vol. 37, pp. 735-742, 2007.

[8] S. Ismail and M. Ramli, "Mechanical strength and drying shrinkage properties of concrete containing treated coarse recycled concrete 
aggregates," Construction and Building Materials, vol. 68, pp. 726$739,2014$.

[9] N. Banthia and R. Gupta, "Hybrid fiber reinforced concrete (HyFRC): fiber synergy in high strength matrices," Materials and Structures vol. 37, pp. 707-716, 2004.

[10] D. C. Teychenné, et al., "Design of normal concrete mixes," Building Research Establishment, Watford, UK1997.

[11] C. X. Qian and P. Stroeven, "Development of hybrid polypropylene-steel fibre-reinforced concrete," Cement and Concrete Research vol. 30, pp. 63-69, 2000.

[12] A. Sivakumar, "Influence of hybrid fibres on the post crack performance of high strength concrete: Part I experimental investigations," Journal of Civil Engineering and Construction Technology, vol. 2, pp. 147-159, 2011.

[13] A. Bentur and S. A. S. Akers, "The microstructure and ageing of cellulose fibre reinforced cement composites cured in a normal environment," International Journal of Cement Composites and Lightweight Concrete, vol. 11, pp. 99-109, 1989.

[14] H. Wu, et al., "Study on Micro-Structure and Durability of Fiber Concrete," Research Journal of Applied Sciences, Engineering and Technology, vol. 5, pp. 659-664, 2013.

[15] D. L. Nguyen, et al., "Size effect on flexural behavior of ultra-highperformance hybrid fiber-reinforced concrete," Composites Part B: Engineering, vol. 45, pp. 1104-1116, 2013.

[16] R. Solís-Carcaño and E. I. Moreno, "Evaluation of concrete made with crushed limestone aggregate based on ultrasonic pulse velocity," Construction and Building Materials, vol. 22, pp. 1225 $1231,2008$. 